\title{
Diet and childhood asthma in a society in transition: a study in urban and rural Saudi Arabia
}

\author{
Nariman Hijazi, Bahaa Abalkhail, Anthony Seaton
}

\begin{abstract}
Background-The causes of the worldwide increases in asthma and allergic diseases in childhood, which seem to relate to increasing prosperity, are unknown. We have previously hypothesised that a reduction in the antioxidant component of the diet is an important factor. An investigation was undertaken of dietary and other risk factors for asthma in Saudi Arabia where major lifestyle differences and prevalences of allergic disease are found in different communities.

Methods-From a cross sectional study of 1444 children with a mean age of 12 (SD 1) years in Jeddah and a group of rural Saudi villages, we selected 114 cases with a history of asthma and wheeze in the last 12 months and 202 controls who had never complained of wheeze or asthma, as recorded on the ISAAC questionnaire. Risk factors for asthma and allergies (family history, social class, infections, immunisations, family size, and diet) were ascertained by questionnaire. Atopy was assessed by skin prick testing.
\end{abstract}

Results-In univariate analyses, family history, atopy, and eating at fast food outlets were significant risk factors for wheezy illness, as were the lowest intakes of milk and vegetables and of fibre, vitamin $\mathrm{E}$, calcium, magnesium, sodium, and potassium. These differences were present also in the urban children considered separately. Sex, family size, social class, infections, and parental smoking showed no relationship to risk. In multiple logistic regression analysis, urban residence, positive skin tests, family history of allergic disease, and the lowest intakes of vitamin $E$, magnesium and sodium related significantly and independently to risk. The lowest tertile of intake of vitamin $E$ was associated with a threefold $(95 \% \mathrm{CI}$ 1.38 to 6.50 ) increase in risk when adjusted for the other factors. Intake of milk and vegetables both showed inverse linear relationships to being a case.

Conclusions-This study suggests that dietary factors during childhood are an important influence in determining the expression of wheezy illness, after allowing for urban/rural residence, sex, family history, and atopy. The findings are consistent with previous studies in adults and with the hypothesis that change in diet has been a determinant of the worldwide increases in asthma and allergies.

(Thorax 2000;55:775-779)

Keywords: asthma; allergy; diet; children; Saudi Arabia
The rise in asthma and allergic disease among children is a matter of worldwide concern. ${ }^{1-3}$ It appears to be associated with lifestyle and social change and to occur with increasing national prosperity. ${ }^{4}$ We have argued that the explanation is likely to lie in an increase in population susceptibility rather than in increasing environmental toxicity, and have suggested that change in diet may have been an important determinant of increased susceptibility. ${ }^{56}$ Initially we suggested that a reduction in antioxidant intake, reflected in the diet of pregnant women, would increase the susceptibility of the newborn baby to allergens. ${ }^{5}$ More recently others have suggested that changes in the fatty acid composition of the diet may increase the risk of children maintaining the Th2 lymphocyte phenotype after birth and thus being predisposed to atopy. ${ }^{7}$ There is now some epidemiological support for dietary antioxidant vitamins being risk factors for asthma in adults, ${ }^{89}$ and for intake of oily fish having a preventive effect in children. ${ }^{10}$

An alternative (or additional) hypothetical explanation of a rise in susceptibility to asthma is that the change from Th2 to Th1 phenotype now occurs less frequently since, in wealthier societies, children no longer suffer the infections that used to promote this change. ${ }^{11}{ }^{12}$ There is epidemiological support for this hypothesis with respect to atopy but little so far with respect to asthma. ${ }^{13-16}$

The best place to study factors associated with the increase in asthma is likely to be a country where the change is still occurring, rather than one where it has become established. We have therefore studied children in Saudi Arabia where prosperity derived from the oil industry has brought rapid social change over three decades, yet where some people live traditional lives, eat a more traditional diet, and where lifestyle cannot be said to be "westernised" save in a few particulars. We have previously reported the results of a prevalence study among primary schoolchildren in this Kingdom, in which we showed that asthmatic and allergic symptoms were significantly more frequent among urban than rural children. ${ }^{17}$ This population also showed smaller differences between Saudi and non-Saudi Arabs, with non-Saudis having generally rather less allergy than Saudis. We have now carried out a study of cases and controls derived from this population to investigate the influence of dietary and other risk factors for asthma. We did not aim to explain urban/rural differences, since many aspects of lifestyle including diet were known to differ substantially between the two communities. Rather, we studied possible determinants of asthmatic symptoms in the 
population as a whole, taking account of urban/rural residence. Our particular interest was to test the a priori hypothesis that a diet low in fruit, vegetables, and antioxidant vitamins is a risk factor for asthmatic symptoms in childhood.

\section{Methods}

Our initial study was of all 1444 Arab children aged 12 (1) years in a socially stratified sample of all schools in Jeddah, Saudi Arabia, and in all the schools in six distant rural villages subject to the same climate. ${ }^{17}$ Permission for the study was obtained from the appropriate authorities. The ISAAC questionnaire, ${ }^{18}$ translated into Arabic, had been used and cases and controls were selected on the basis of answers to this questionnaire. Cases were defined as all children who had answered positively to both "Have you had wheezing or whistling in the chest in the last 12 months?" and "Have you ever had asthma?" The second question was intended to exclude those in whom recent symptoms had followed an infection. Controls, selected randomly from the same school and classes as cases, gave negative answers to these questions and to "Have you ever had wheezing or whistling in your chest at any time in the past?" Among the 1444 subjects there were 162 potential cases and 398 potential controls, of whom 114 (100 urban) and 202 (142 urban), respectively, were studied. Non-participation was due either to having moved away or to failure to obtain parental consent, which was otherwise obtained for all children. No systematic differences in symptom prevalences between participants and non-participants were found on study of the original questionnaires.

Each participating child was skin tested to the allergens Dermatophagoides pteronyssinus and $D$ farinae, cat, cockroach and Cladosporium $\mathrm{sp}$. The children's parents were asked to complete a questionnaire designed to elicit information on each participating child's previous infectious illnesses and immunisations, the education and occupation of the parents, family history of allergic disease, parental smoking, breast feeding, animals in the house, and family size. In addition, a detailed semi-quantitative food frequency questionnaire adapted for use with the Arabic diet and a simple questionnaire enquiring of the types of food eaten by the child were completed by the mother. Food composition tables for use in Asia and the US handbook of food composition were used for estimating some of the nutrients, ${ }^{19}$ while local foods not included in the tables were derived from previous studies. ${ }^{20}$ Dietary supplements were rarely used by the children and were not taken into account.

Daily intakes of specific nutrients were estimated by multiplying frequency of consumption by standard portion sizes and by the nutrient content of the food items. Intake from supplements was not included. Values for nutrient intake were adjusted for total energy intake by the method of Willett and Stampfer. ${ }^{21}$

The data were coded, entered into a database, and analysed by SPSS. Differences between cases and controls were tested by $t$ test and $\chi^{2}$ test as relevant. Dietary data proved to be distributed close to normally in all cases. Interactions between independent effects of factors shown to be significant in these univariate analyses were investigated by multiple logistic regression, examining the detailed nutritional factors and general eating habits separately. The goodness of fit of all logistic regressions was tested and found to be adequate in all models reported in the study. ${ }^{22}$

\section{Results}

FAMILY HISTORY, ATOPY, INFECTIONS, FAMILY SIZE, AND OTHER FACTORS

Family history of asthma and the presence of positive skin tests were strongly related to being a case (table 1), both overall and in urban and rural children separately. Rhinitis and itchy eyes showed similar associations. $72 \%$ of urban and $29 \%$ of rural cases, and $38 \%$ of urban and $3 \%$ of rural controls had one or more positive skin tests, mite being the most common in both areas. Sibship size averaged 6.4 among cases and 5.8 among controls and was related neither to symptoms nor to atopy. Hospital admissions, mainly for respiratory disease, were significantly more frequent in cases, but none of the common childhood infections related to case-control status. Immunisation to common diseases including BCG was almost universal,

Table 1 Skin tests and family history of asthma in cases and controls (\%)

\begin{tabular}{llcc}
\hline Risk factor & $\begin{array}{l}\text { Cases } \\
(n=114)\end{array}$ & $\begin{array}{l}\text { Controls } \\
(n=202)\end{array}$ & $\begin{array}{l}p \text { value } \\
\left(\chi^{2} \text { test }\right)\end{array}$ \\
\hline Father asthma & 17.5 & 5.9 & 0.001 \\
Mother asthma & 14.9 & 7.9 & 0.05 \\
Sibling asthma & 60.5 & 15.8 & $<0.001$ \\
Any skin test +ve & 66.7 & 27.7 & $<0.001$ \\
$\quad$ D pteronyssinus & 64.0 & 22.3 & $<0.001$ \\
Cat & 26.3 & 9.4 & $<0.001$ \\
Cladosporium sp & 14.9 & 4.5 & 0.001 \\
Cockroach & 8.8 & 2.0 & 0.004
\end{tabular}

Table 2 Dietary habits of cases and controls (\%)

\begin{tabular}{lccc}
\hline & $\begin{array}{l}\text { Cases } \\
(n=114)\end{array}$ & $\begin{array}{l}\text { Controls } \\
(n=202)\end{array}$ & $\begin{array}{l}\text { p value } \\
\left(\chi^{2} \text { test }\right)\end{array}$ \\
\hline $\begin{array}{l}\text { Going to fast food outlet } \\
\quad\end{array}$ & 7.9 & 8.9 & 0.008 \\
$\quad$ Often & 55.3 & 39.1 & \\
$\quad$ Sometimes & 21.9 & 21.3 & \\
$\quad$ Rarely & 14.9 & 30.7 & \\
$\quad$ Never & & & \\
Animal fat for cooking & & & \\
$\quad$ Often & 7.9 & 10.9 & 0.062 \\
$\quad$ Sometimes & 21.9 & 25.2 & \\
$\quad$ Rarely & 18.4 & 27.2 & \\
$\quad$ Never & 51.8 & 36.6 & \\
Eating fish & & & \\
$\quad$ Often & 10.5 & 10.9 & 0.073 \\
$\quad$ Sometimes & 43.0 & 51.9 & \\
$\quad$ Rarely & 35.1 & 21.8 & \\
$\quad$ Never & 11.4 & 15.4 & \\
\end{tabular}

${ }^{\star}$ In Arabic these terms indicate a progressive decrease in frequency.

Table 3 Mean (SD) daily number of portions of food groups in cases and controls (\%)

\begin{tabular}{llll}
\hline Food & $\begin{array}{l}\text { Cases } \\
(n=114)\end{array}$ & $\begin{array}{l}\text { Controls } \\
(n=202)\end{array}$ & $\begin{array}{l}p \text { value } \\
(\text { t test })\end{array}$ \\
\hline Rice & $3.38(1.44)$ & $3.37(1.15)$ & 0.95 \\
Milk & $2.35(1.30)$ & $2.70(1.28)$ & 0.024 \\
Meat & $2.26(1.05)$ & $2.14(1.13)$ & 0.49 \\
Fruit & $2.62(1.55)$ & $2.82(1.47)$ & 0.24 \\
Vegetables & $4.16(2.04)$ & $4.87(2.40)$ & 0.007 \\
\hline
\end{tabular}


Table 4 Energy adjusted daily nutrient intakes of cases and controls

\begin{tabular}{|c|c|c|c|c|c|}
\hline \multirow{2}{*}{$\begin{array}{l}\text { Nutrient } \\
\text { Carbohydrate (g) }\end{array}$} & \multicolumn{2}{|c|}{$\begin{array}{l}\text { Cases } \\
(n=114)\end{array}$} & \multicolumn{2}{|c|}{$\begin{array}{l}\text { Controls } \\
(n=202)\end{array}$} & \multirow{2}{*}{$\begin{array}{r}\begin{array}{c}p \text { value } \\
\text { (t test) }\end{array} \\
0.95\end{array}$} \\
\hline & 393 & (51) & 393 & (51) & \\
\hline Protein $(\mathrm{g})$ & 143 & (18) & 143 & (18) & 0.90 \\
\hline Cholesterol $(\mathrm{mg})^{\star}$ & 639 & (199) & 609 & (189) & 0.20 \\
\hline Polyunsaturated fatty acids $(\mathrm{g})^{\star}$ & 20.7 & (3.6) & 20.3 & (3.7) & 0.29 \\
\hline Monounsaturated fatty acids $(\mathrm{g})^{\star}$ & 40.0 & (3.3) & 40.6 & (2.9) & 0.12 \\
\hline Saturated fatty acids $(\mathrm{g})^{\star}$ & 49.7 & $(4.3)$ & 50.6 & $(4.9)$ & 0.09 \\
\hline Fibre $(\mathrm{g})$ & 30.6 & $(8.0)$ & 31.2 & $(8.4)$ & 0.009 \\
\hline Vitamin A (RE) & 3483 & (2309) & 3188 & (1932) & 0.23 \\
\hline Vitamin C (mg) & 139 & $(66)$ & 150 & $(67)$ & 0.136 \\
\hline Vitamin E (mg) & 7.16 & $(1.56)$ & 7.7 & $(1.72)$ & 0.005 \\
\hline Zinc (mg) & 14.2 & $(2.2)$ & 14.7 & $(2.3)$ & 0.09 \\
\hline Niacin (mg) & 31.2 & $(5.27)$ & 29.9 & $(4.8)$ & 0.03 \\
\hline Magnesium (mg) & 374 & $(60)$ & 400 & (71) & 0.001 \\
\hline Calcium (mg) & 1467 & $(279)$ & 1605 & $(332)$ & $<0.001$ \\
\hline Selenium (mg) & 0.24 & $(0.05)$ & 0.2 & $(0.06)$ & 0.56 \\
\hline Sodium (mg) & 2313 & $(401)$ & 2508 & $(406)$ & $<0.001$ \\
\hline Potassium & 4581 & (614) & 4824 & (711) & 0.002 \\
\hline
\end{tabular}

Values are mean (SD)

*Also adjusted for total fat.

and only rubella immunisation showed a significant positive association with being a case $(88.6 \%$ versus $77.2 \%, \mathrm{p}=0.012)$. Parental smoking and educational level, having an animal in the house, and breast feeding of the child were not related to being a case or a control subject.

\section{DIETARY FACTORS}

The frequency of eating at a fast food outlet was significantly related to being a case (table 2) whereas frequency of use of animal or vegetable oil in cooking and eating fish was not. Of the major food groups, cases consumed significantly less milk and vegetables than control subjects (table 3 ) and, of the micronutrients adjusted for energy intake, cases ate significantly less fibre, vitamin E, magnesium, calcium, sodium, and potassium than controls (table 4). These analyses were repeated in the urban and rural children separately. The small numbers of rural children did not allow sufficient power to demonstrate significant differences, although the trends were in the same direction. Among the urban children the lowest intakes of vegetables, vitamin E, calcium, magnesium, sodium, and zinc were significantly $(p<0.01)$ associated with being a case.

Table 5 Mutually adjusted independent risk factors associated with being a case in the multiple regression analysis

\begin{tabular}{llll}
\hline Risk factor & $\begin{array}{l}\text { Adjusted } \\
\text { odds ratio }\end{array}$ & $\begin{array}{l}95 \% \text { confidence } \\
\text { intervals }\end{array}$ & p value \\
\hline $\begin{array}{l}\text { Place of residence } \\
\quad \text { Rural }\end{array}$ & 1.0 & & \\
$\quad$ Urban & 3.46 & 1.48 to 8.06 & 0.004 \\
$\begin{array}{l}\text { Nationality } \\
\quad \text { Non-Saudi }\end{array}$ & 1.0 & & \\
$\quad$ Saudi & 2.09 & 0.94 to 4.65 & 0.07 \\
$\begin{array}{l}\text { Sex } \\
\quad \text { Female }\end{array}$ & 1.0 & & \\
$\quad$ Male & 0.63 & 0.32 to 1.32 & 0.17 \\
$\begin{array}{l}\text { Mother's education } \\
\quad \text { None }\end{array}$ & 1.0 & & \\
$\quad$ Primary & 0.30 & 0.11 to 0.77 & \\
$\quad \begin{array}{l}\text { Secondary } \\
\quad \text { Higher }\end{array}$ & 0.54 & 0.21 to 1.42 & \\
Family history of asthma/allergy & 0.22 to 0.92 & 0.04 \\
$\quad$ No & & & \\
$\quad$ Yes & 1.0 & & \\
Positive skin test & 9.22 & 4.93 to 17.24 & $<0.001$ \\
$\quad$ No & 1.0 & & \\
$\quad$ Yes & 4.39 & 2.34 to 8.23 & $<0.001$ \\
\hline
\end{tabular}

Table 6 Nutritional risk factors associated with being a case, adjusted by multiple regression analysis for all the variables in table 5 and for social class

\begin{tabular}{|c|c|c|}
\hline $\begin{array}{l}\text { Nutrient } \\
\text { (tertiles of intake) }\end{array}$ & Odds ratio & $\begin{array}{l}95 \% \text { confidence } \\
\text { interval }\end{array}$ \\
\hline \multicolumn{3}{|l|}{ Calcium } \\
\hline High & 1.0 & \\
\hline Medium & 1.58 & 0.77 to 3.23 \\
\hline Low & 1.88 & 0.91 to 3.89 \\
\hline \multicolumn{3}{|l|}{ Fibre } \\
\hline High & 1.0 & \\
\hline Medium & 1.50 & 0.72 to 3.12 \\
\hline Low & 1.79 & 0.87 to 3.67 \\
\hline \multicolumn{3}{|l|}{ Vitamin E } \\
\hline High & 1.0 & \\
\hline Medium & 1.63 & 0.77 to 3.45 \\
\hline Low & $\star 3.00$ & 1.38 to 6.50 \\
\hline \multicolumn{3}{|l|}{ Vitamin C } \\
\hline High & 1.0 & \\
\hline Medium & 1.81 & 0.88 to 3.72 \\
\hline Low & 1.78 & 0.86 to 3.67 \\
\hline \multicolumn{3}{|l|}{ Magnesium } \\
\hline High & 1.0 & \\
\hline Medium & 1.39 & 0.68 to 2.87 \\
\hline Low & 2.29 & 1.12 to 4.69 \\
\hline \multicolumn{3}{|l|}{ Sodium } \\
\hline High & 1.0 & \\
\hline Medium & 2.01 & 0.96 to 4.21 \\
\hline Low & $\star 2.88$ & 1.42 to 5.87 \\
\hline
\end{tabular}

*Test for linear trend from logistic model $(\mathrm{p}<0.02)$.

Table 7 Food groups associated with being a case, adjusted as in table 6

\begin{tabular}{lllll}
\hline Food & $\begin{array}{l}\text { Portions/ } \\
\text { day }\end{array}$ & Odds ratio & $\begin{array}{l}95 \% \\
\text { confidence } \\
\text { intervals }\end{array}$ & $\begin{array}{l}\text { p (test for } \\
\text { linear trend) }\end{array}$ \\
\hline Vegetables & $>3$ & 1.0 & & \\
& $2-3$ & 2.45 & 1.30 to 4.65 & \\
& $<2$ & 2.83 & 0.98 to 8.09 & 0.01 \\
Milk & $>3$ & 1.0 & & \\
& $2-3$ & 1.51 & 0.70 to 3.26 & \\
& $<2$ & 2.40 & 1.21 to 4.75 & 0.04 \\
\hline
\end{tabular}

In the multiple regression analysis, after mutual adjustment, place of residence (urban/ rural), family history of asthma or hay fever, and presence of positive skin tests related significantly, as expected, to case status (table 5). Higher maternal education appeared to have a protective effect. In addition, when adjusted for the above factors, for sex, and for social class, the lowest tertiles of intake of vitamin $\mathrm{E}$ and sodium appeared to be significant independent risk factors (table 6). The association with vitamin $\mathrm{E}$ remained significant when either or both of sodium and magnesium were entered into the model, but the minerals lost their statistical significance when entered with vitamin E. Separate analyses using the same model showed that intakes of milk and vegetables were both inversely linearly related to the risk of being a case (table 7), but frequency of going to a fast food outlet was not. Both milk and vegetables lost statistical significance when entered with each other, but the odds ratios were little altered.

\section{Discussion}

The rise in asthma and allergic diseases in association with national prosperity speaks for major environmental influences on the expression of relevant genes. Our original study in Saudi Arabia showed asthmatic symptoms to be 2-3 times more common in a developed urban environment than in rural villages. ${ }^{17} \mathrm{We}$ have now shown that, after allowing for other 
important determinants including place of residence, dietary factors are associated with a 2-3 fold increase in risk of having such symptoms. This finding is of considerable public health importance.

As far as we are aware, this is the first study to have reported an investigation of total diet as a risk factor for childhood asthma. One previous study has suggested that consumption of fresh fruit may protect lung function in children $^{23}$ and another has shown that fish oil may protect against asthma. ${ }^{10}$ We have used a questionnaire based on one widely used and validated in studies in Scotland, including our own studies, but had to adapt it to take account of the Saudi diet; no fully validated tool exists for this at present. In general, food frequency questionnaires provide useful information on intake in groups rather than individuals since, while it is difficult to standardise a portion, differences in interpretation of what this means average out in groups. ${ }^{24}$ Our food intake results should not therefore be taken as applicable to individuals, but may be taken as a reasonable basis for comparisons between groups.

In two separate case-control studies in Scottish adults we have found remarkably similar results. In one, based on a cross sectional study of a rural population, we showed that a low intake of vitamin $\mathrm{C}$ was associated with bronchial hyperreactivity. ${ }^{8}$ In the other, nested in a 30 year cohort study, we found low intake of vitamin $\mathrm{E}$ and reduced blood levels of $\alpha$-tocopherol and ascorbate to be associated with adult onset wheezy illness. ${ }^{9}$ In the latter study there appeared to be some confounding by social class, the effect being more clearly evident in the manual group. Both studies also suggested that fat intake may be relevant in that, in the first study, a low intake of saturated and mono-unsaturated fatty acids appeared protective against hyperreactivity while, in the second, high blood concentrations of triglycerides were associated with adult onset wheeze.

The Saudi diet is traditionally based on Arabic foods and bears little superficial resemblance to the western diet. Pasteurised cows' and goats' milk, rice, vegetables, lamb, chicken, and dates and other local fruits form the basis. However, with increasing prosperity and commercial exposure, there has been an influx over some three decades of western-type frozen and prepared foods in supermarkets and restaurants. Our earlier study was intended to show whether or not prevalence of asthma differed between the modern city of Jeddah and rural villages where the traditional lifestyle, including dietary habits, persisted. Our observation that asthma is more common in the city than in the rural villages gave us an opportunity to investigate dietary and other risk factors across the whole population in what appeared to be an evolving situation. This rural/urban difference has been observed in other countries in different stages of development, ${ }^{25}$ but is not apparent in developed countries and is unlikely to be related to air pollution. ${ }^{26}$ It is generally thought to be due to lifestyle factors. Before we started we were aware that there were substantial differences in diet as well as in other lifestyle factors between the two communities, the rural people relying more on locally grown fresh foods and less on imported and processed foods. However, the study was not planned to test this observation but rather to use the wide range of asthma prevalences previously demonstrated to investigate factors that might explain them across the whole population.

The currently most plausible explanations of the rise in asthma and allergic diseases are that it is the result of a fall in early childhood infections ${ }^{27} 28$ and/or a change in diet. ${ }^{5}$ Epidemiological evidence suggests that early infections may decrease the risk of atopy but not, apparently, asthma. ${ }^{13-16}$ Diet, however, may theoretically influence both early $\mathrm{T}$ helper cell differentiation and also lung defences against allergens. The epidemiological evidence now suggests that it may act throughout life. The fatty acid hypothesis proposes that a change in the dietary balance from predominantly $\omega-3$ to $\omega-6$ polyunsaturated fatty acids has increased susceptibility to allergies by promoting synthesis of prostenoids and influencing the differentiation of $\mathrm{T}$ helper lymphocytes towards the Th2 subtype. ${ }^{7}$ There is also some evidence that the balance of unsaturated fatty acids in the diet may act directly to influence gene expression. ${ }^{29}$ Unfortunately, food frequency questionnaires to date have not allowed differentiation of the fatty acids, but our current studies in the UK are addressing this. Vitamin $\mathrm{E}$ has been shown in a murine model to promote the Th1 subtype, ${ }^{30}$ while one of the functions of vitamin $\mathrm{C}$ is to regenerate vitamin $\mathrm{E}$ from the oxidised tocopheroxyl radical. Moreover, both vitamins may act to protect airways against oxidant attack. Together with this theoretical framework, accumulating epidemiological evidence, most recently showing ecological associations between the intake of trans fatty acids (mainly derived from industrially hydrogenated fats in spreads) and the national prevalence of asthma across countries, ${ }^{31}$ points towards an important role of diet in determining the expression of the disease.

The role of salt in this study merits some comment, since our findings contrast with earlier suggestions that a high salt intake increases the risk of asthma (although a more recent study has not confirmed this ${ }^{32}$ ). Our study was carried out in a country where the temperature requires a high salt intake for health, and it may be that a low intake is simply a marker for an otherwise poor diet in these circumstances. However, the questionnaire we used may be an inappropriate tool for demonstration of salt intake and further studies would be necessary to test this observation.

Our current research is investigating prospectively the influence of the diet of pregnant women on development of allergic disease in the offspring. We believe the time may be close for consideration of intervention trials. These should probably be based on dietary advice to increase fruit and vegetable intake rather than on supplementation, since we think it likely that a move away from the combination of different nutrients in the balanced diet with which 
we have evolved, rather than the exclusion or inclusion of particular micronutrients, has been responsible for the observed changes in disease prevalence.

This study forms part of Mrs Hijazi's PhD awarded by the University of Aberdeen. The authors are grateful to their respective universities for funding, to the children and their parents for taking part, and to Dr Mohammed Kamal for assistance with data gathering. They also thank Dr Coreen Bodner and Profes-
sors David Godden and Peter Burney for their helpful comments.

1 Burney PGJ, Chinn S, Rhona RJ. Has the prevalence of asthma increased in children? Evidence from the national study of health and growth. $B M F$ 1990;300:1306-10

2 Peat JK, van den Berg RH, Green WF, et al. Changing prevalence of asthma in Australian children. BMF 1994 308:1591-6.

3 Omran M, Russell G. Continuing increase in respiratory symptoms and atopy in Aberdeen schoolchildren. $B M{ }^{f}$ 1996;312:34.

4 Woolcock AJ. Asthma: disease of a modern lifestyle. Med $\mathcal{F}$ Aust 1996;165:358-9.

5 Seaton A, Godden DJ, Brown K. Increase in asthma: a more toxic environment or a more susceptible population? Thorax 1994;49:171-4.

6 Seaton A, Soutar A, Mullins J. The increase in hay fever: pollen, particulate matter and $\mathrm{SO}_{2}$ in ambient air. $Q \mathcal{F} \mathrm{Med}$ pollen, particula

7 Black PN, Sharp S. Dietary fat and asthma: is there a connection? Eur Respir f 1997;10:6-12.

8 Soutar A, Seaton A, Brown K. Bronchial reactivity and dietary antioxidants. Thorax 1997;52:166-70.

9 Bodner C, Godden D, Little J, et al. Antioxidant intake and adult-onset wheeze: a case-control study. Eur Respir $f$ 1999;13:22-30.

10 Hodge L, Salome CM, Peat JK, et al. Consumption of oily fish and childhood asthma risk. Med f Aust 1996;164:13740.

11 Shaheen SO. Changing patterns of childhood infection and the rise in allergic disease. Clin Exp Allergy 1995;25:10347 the

12 Shaheen S. Discovering the causes of atopy. Patterns of childhood infection and fetal growth may be implicated. childhood infection an

13 Shaheen SO, Aaby P, Hall AJ, et al. Measles and atopy in Guinea-Bissau. Lancet 1996;347:1792-6.

14 Shirakawa T, Enomoto T, Shimazu S-I, et al. The inverse association between tuberculin responses and atopic disorder. Science 1997;275:77-9.
15 Matricardi PM, Rosmini F, Ferrigno L, et al. Cross sectional retrospective study of prevalence of atopy among Italian military students with antibo

16 Bodner C, Godden D, Seaton A. Family size, childhood infections and atopic diseases. Thorax 1998;53:28-32.

17 Hijazi N, Abalkhail B, Seaton A. Asthma and respiratory symptoms in urban and rural Saudi Arabia. Eur Respir $\mathcal{F}$ 1998;12:41-4.

18 Pearce N, Weiland S, Keil U, et al. Self-reported prevalence of asthma symptoms in children in Australia, England, Germany and New Zealand: an international comparison using the ISAAC protocol. Eur Respir F 1993;6:1455-61.

19 Food composition tables for use in East Asia. United States Department of Health, Education and Welfare and United Nations Food and Agriculture Organisation, 1972.

20 Abalkhail B. Hypercholesterolemia and susceptibility to cardiovascular diseases among white and blue collar workcardiovascular diseases among white and b
ers in Jeddah. Saudi Med f 1998;19:123-9.

21 Willett WC, Stampfer MJ. Total energy intake: implications for epidemiologic analyses. Am 7 Epidemiol 1986;124:1727 .

22 Hosmer DW, Lemeshow S. Applied logistic regression. New York: Wiley, 1989

23 Cook DG, Carey IM, Whincup PH, et al. Effect of fresh fruit consumption on lung function and wheeze in children. Thorax 1997;52:628-33.

24 Block G, Hartman AM, Dresser CM, et al. Data-based approach to diet questionnaire design and testing. $\mathrm{Am} \mathcal{F}$ Epidemiol 1986;79:83-91.

25 Yemaneberhan H, Bekele Z, Venn A, et al. Prevalence of wheeze and asthma and relation to atopy in urban and rural Ethiopia. Lancet 1997;350:85-90.

26 Austin JB, Russell G, Adam MG, et al. Prevalence of asthma and wheeze in the Highlands of Scotland. Arch Dis Child 1994;71:211-6.

27 Strachan DP, Harkins LS, Johnston IDA, et al. Childhood antecedents of allergic sensitization in young British adults. f Allergy Clin Immunol 1997;99:6-12.

28 Strachan DP, Taylor EM, Carpenter RG. Family structure, neonatal infection, and hayfever in adolescence. Arch Dis Child 1996;74:422-6.

29 Simopoulos AP. The role of fatty acids in gene expression: health implications. Ann Nutr Metab 1996;40:303-11.

30 Wang Y, Huang DS, Eskelson CD, et al. Long term dietary vitamin $\mathrm{E}$ retards development of retrovirus-induced disregulatic

31 Weiland SK, von Mutius $\mathrm{E}, \mathrm{Husing} \mathrm{A}$, et al. Intake of trans fatty acids and prevalence of childhood asthma and fatty acids and prevalence of childhood

32 Demissie K, Ernst P, Gray DK, et al. Usual dietary salt intake and asthma in children: a case-control study. Thorax 1996;51:59-63. 